- Notes -

\title{
Reactive Extraction of 1,3-Propanediol with Aldehydes in the Presence of a Hydrophobic Acidic Ionic Liquid as a Catalyst
}

\author{
Michiaki MATSUMOTO,* Katsuya NAGAI and Kazuo KONDO \\ Department of Chemical Engineering and Materials Science \\ Doshisha University, Kyotanabe, Kyoto 610-0321 Japan \\ (Received December 1, 2014; Accepted January 15, 2015)
}

The biological production of 1,3-propanediol from glycerol, which is a by-product in a bio-diesel production process, is of great interest. However, major difficulties still exist in downstream processing because 1,3-propanediol has a high boiling point. In this study, reactive extraction with aldehydes in the presence of a hydrophobic acidic ionic liquid as an acidic catalyst was used to extract 1,3-propanediol from an aqueous solution. Hydrophobic acidic ionic liquids have successfully played the role of acidic catalysts for acetalization as well as hydrochloric acid. Aromatic compounds as diluents were preferable for this acetalization. Conversion of $60 \mathrm{~g} / \mathrm{dm}^{3}$ of 1,3 propanediol reached $96 \%$ at a concentration of $4.0 \mathrm{~mol} / \mathrm{dm}^{3}$ of 1-butanal in toluene.

\section{Introduction}

1,3-Propanediol has been mainly used as a commercial solvent and a raw material of the industrial product. Recently, 1,3-propanediol has attracted attention as an important monomer of poly(trimethylene terephthalate) (PTT), because of several unique properties of PTT for the production of fibers [1-3]. Although 1,3-propanediol was produced by chemical conversion of acrolein, in recent times sustainable bio-chemicals produced from renewable resources have been paid more attention, as resources as fossil fuels become increasingly scarce. The alternative route utilizing biomass is also of significant interested in 1,3-propanediol production. Therefore, studies on the bioproduction of 1,3-propanediol from glycerol, which is a renewable resource formed as a by-product of biodiesel production, have greatly increased [2,3]. Due to the high boiling point $\left(214^{\circ} \mathrm{C}\right)$ and high hydrophilicity of 1,3-propanediol, its recovery from fermentation broths becomes an important factor in its industrial production. The cost of its separation is reported to be up to 50-70\% of the production cost [1]. The development of an efficient and economic recovery process is desired to improve the economics of the production process based on a biomass route. Pervaporation [4], extraction [5,10,14], reactive extraction [6-9,11,13,15,19,27], vacuum distillation [16], aqueous two phase extraction [12,17,18,20,22-26] and adsorption [21] have been proposed as separation methods. Compared with other separation techniques, extraction is considered to possess several advantages, such as large throughput and low energy consumption. Solvent extraction with water-immiscible organic solvents (physical extraction), such as ethyl acetate produce low separation efficiencies due to the limitation of the solubility of 1,3-propanediol [1]. An alternative way of physical extraction is to use an aqueous two-phase extraction system, which has been widely applied in the 
separation of bio-molecules, such as proteins and nucleic acids because of its simplicity, low energy consumption, and easy scale up [28]. However, in aqueous two-phase extraction, recovery of the product from the extracted phase is an issue that often arises. Alternatively, reactive extraction methods using a reversible reaction such as esterification with boronates [27] and acetalization with aldehydes in the presence of an acid catalyst, as shown in Scheme 1, [6-9,11,13,15,19] were proposed to selectively separate 1,3-propanediol. In our previous paper [27], reactive extraction with boronates gave a low partition coefficient due to poor reactivity. Therefore, we propose the reactive extraction with aldehydes in the presence of an acid catalyst. The most frequently used catalysts in the acetalization process were strongly acidic cation-exchange polymeric resins. Recently Boonoun et al. [15] developed a low-cost sulfonated carbon-based catalyst. Furthermore, use of water-soluble catalysts such as sulfuric acid [9] and acidic ionic liquids, $[\mathrm{bmim}]\left[\mathrm{HSO}_{4}\right]$ and $[\mathrm{Hmim}]\left[\mathrm{HSO}_{4}\right]$, have been proposed. [30,32] If an oil-soluble acidic ionic liquid plays a catalytic role for acetalization, it may remain in the organic solution after the acetal products of 1,3-propanediol were removed by stripping or distillation from the organic solution and then may be reused as catalyst .

In this study, we examined whether a hydrophobic acidic ionic liquid functions as a catalyst for acetalization and carried out reactive extraction with aldehydes in the presence of a hydrophobic acidic ionic liquid to extract 1,3-propanediol from the aqueous solution. We used trioctyl(propyl-3-sulfonic acid) ammonium bis (trifluoromethylsulfonyl)imide, (abbreviated as HBAIL) developed by Gu et al [29] as the hydrophobic acidic ionic liquid which was reported to be easily recovered after the reaction and reused in the next run without activity loss because it is not soluble in water.

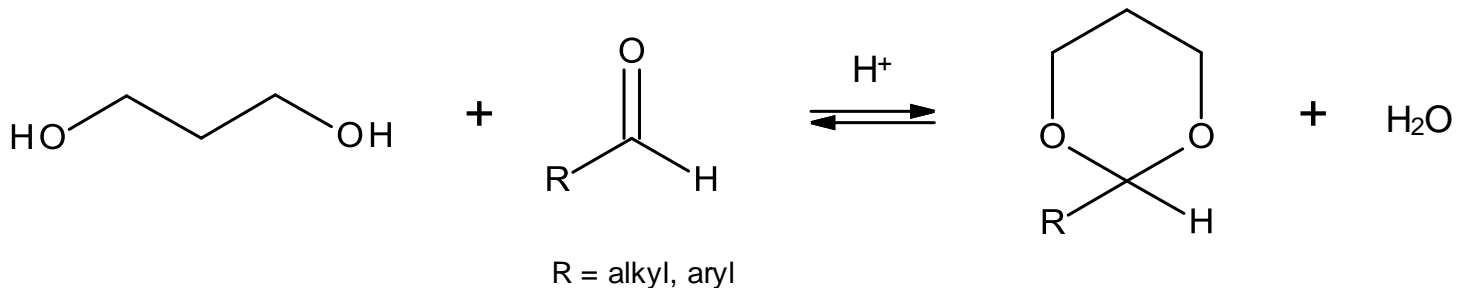

Scheme 1. Acetalization of 1,3-propanediol by aldehydes.

\section{Experimental}

\subsection{Chemicals}

The hydrophobic Brønsted acidic ionic-liquid, HBAIL was prepared according to the procedure reported by $\mathrm{Gu}$ et al. [29] and its molecular structure is shown in Figure 1. The aldehydes used were 1-butanal, 1-hexanal, 1-octanal and benzaldehyde. Organic solvents used as diluents for HBAIL and the aldehydes were $o$-xylene, cyclohexane, butylbenzene,

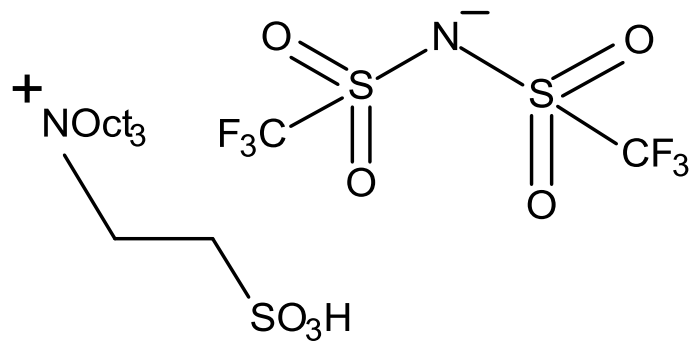

Figure 1. Molecular structure of HBAIL. ethylbenzene, toluene, 1-decanol and 1-octanol. All aldehydes and organic solvents of GR grade were used as received. 1,3-Propanediol was used without further purification. 


\subsection{Reactive extraction}

Aqueous solutions were prepared by dissolving 1,3-propanediol in deionized water, with its concentration adjusted to $0.79 \mathrm{~mol} / \mathrm{dm}^{3}\left(60 \mathrm{~g} / \mathrm{dm}^{3}\right)$. This concentration was selected because the final concentration of 1,3-propanediol in the fermentation broth was $30 \sim 130 \mathrm{~g} / \mathrm{dm}^{3}$ [8]. Organic solutions were prepared by dissolving $1.58 \mathrm{~mol} / \mathrm{dm}^{3}$ aldehyde and $0.029 \mathrm{~mol} / \mathrm{dm}^{3}\left(14 \mathrm{~g} / \mathrm{dm}^{3}\right)$ HBAIL in an organic solvent. Equal volumes $\left(4 \mathrm{~cm}^{3}\right)$ of the aqueous and organic solutions were mixed in a vial tube and shaken at $303 \mathrm{~K}$ for $24 \mathrm{~h}$ to attain extraction equilibrium. After the two phases were separated by centrifugation at $4000 \mathrm{rpm}$ for $10 \mathrm{~min}$, samples were taken from the aqueous solution. The $\mathrm{pH}$ values of the aqueous solutions before and after equilibration were determined by a Horiba F-12 pH meter.

1,3-Propanediol concentrations in the samples were determined by HPLC (Shimadzu LC-10ADvp) with a refractive index detector (Shimadzu RID-10A). Analyses were performed using a Shodex SUGAR SH-1011 (Showa Denko) column and a $5 \mathrm{mmol} / \mathrm{dm}^{3} \quad \mathrm{H}_{2} \mathrm{SO}_{4}$ solution as the mobile phase. Conversion was calculated by the concentration difference in 1,3-propanediol between the initial and equilibrium states.

\section{Results and Discussion}

In order to examine the effect of acid catalysts on the reaction of Eq. (1), two catalytic reactions were carried out using 1-butanal in the presence of $\mathrm{HCl}$ in the aqueous phase and in the presence of HBAIL in $o$-xylene. Figure 2 shows the effect of $\mathrm{HCl}$ and HBAIL concentrations on the conversion of 1,3-propanediol. Conversion increased with increasing $\mathrm{HCl}$ and HBAIL concentrations. It was found that HBAIL effectively played a role of acid catalyst in the acetalization as well as $\mathrm{HCl}$. Conversions of 1,3-propanediol with aldehydes in the presence of the water-soluble ionic liquid, [bmim] $\left[\mathrm{HSO}_{4}\right]$, and microwave irradiation were reported to be within 65-98\%. [30] The highest conversion of 1,2-propanediol with benzaldehyde in the presence of [bmim] $\left[\mathrm{HSO}_{4}\right]$ was $78.7 \%$. [32] The catalytic performance of HBAIL was found to be

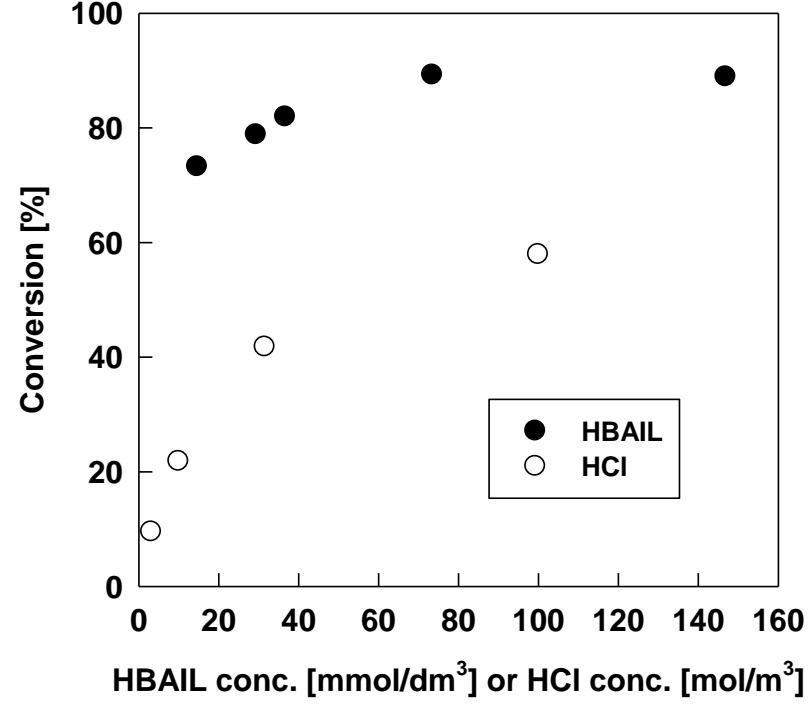

Figure 2. Effect of acid catalysts on the acetalization of 1,3-propanenediol with1-butanal.

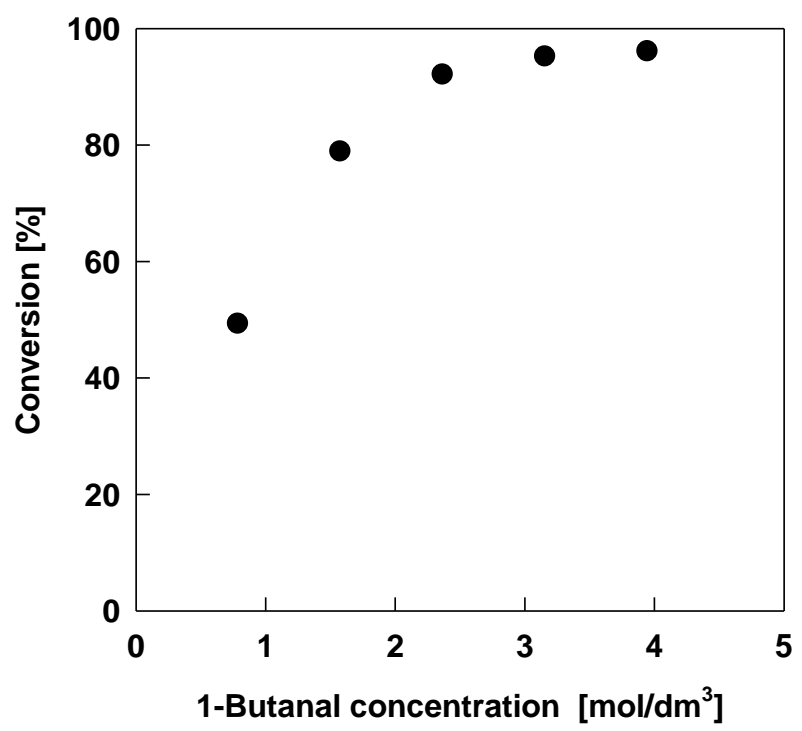

Figure 3. Effect of 1-butanal concentration on acetalization using toluene. 
comparable to those with water-soluble ionic liquids reported previously. [30,32] Acetal produced using HBAIL is distributed to the organic phase due to its high distribution ratio (=27.5). [8] Hereafter, we used a concentration of $29 \mathrm{mmol} / \mathrm{dm}^{3}$ of HBAIL in order to clarify the effects of 1-butanal concentration and solvents.

Figure 3 shows the effect of 1-butanal on the conversion using toluene as the diluent. As expected from Eq. (1), the conversion increased with increasing 1-butanal concentration. Conversion reached $96 \%$ at a concentration of $4.0 \mathrm{~mol} / \mathrm{dm}^{3}$ of 1-butanal.

Next, we examined the effect of diluents and aldehydes on the HBAIL-catalytic reaction and the results were summarized in Table 1. Malinowski et al. [6,7] recommended aromatic hydrocarbons from the viewpoints of the distribution ratios of the products and their water solubilities. From Table 1,o-xylene and ethylbenzene gave the best conversion. However, because ethylbenzene is less toxic than $o$-xylene [31], ethylbenzene would be preferred. An increase in the alkyl chain length on the formyl group depressed the conversion. This may be due to the lower solubility of the lipophilic aldehydes in the aqueous solution, where the acetalization reaction occurred.

Table 1. Effect of diluents and aldehydes on the HBAIL-catalytic reaction.

\begin{tabular}{ccc}
\hline Aldehydes & Diluents & $\begin{array}{c}\text { Conversion at } \\
\text { equilibrium [\%] }\end{array}$ \\
\hline 1-Butanal & $o$-Xylene & 87 \\
& Ethylbenzene & 85 \\
& Toluene & 79 \\
& Butylbenzene & 58 \\
& 1-Octanol & 15 \\
& 1-Decanol & 6 \\
\hline 1-Hexanal & Ethylbenzene & 77 \\
1-Octanal & & 64 \\
Benzaldehyde & & 13 \\
\hline
\end{tabular}

*HBAIL was not dissolved in cyclohexane.

\section{Conclusion}

In this study, reactive extraction utilizing acetalization in the presence of HBAIL was used to extract 1,3-propanediol from aqueous solution. HBAIL successfully played a role of the acidic catalyst for acetalization. Aromatic compounds as diluents were preferable for this acetalization. Conversion of 60 $\mathrm{g} / \mathrm{dm}^{3}$ of 1,3-propanediol reached $96 \%$ at a concentration of $4.0 \mathrm{~mol} / \mathrm{dm}^{3}$ of 1-butanal in toluene. It was found that acetalization with aldehydes using HBAIL can provide a successful separation process for 1,3-propanediol.

\section{Acknowledgement}

This work was supported by a Grant-in-Aid for Scientific Research (C) (No. 25420813) from the Ministry of Education, Culture, Sports, Science and Technology, Japan. 


\section{References}

1) Z. L. Xiu, A. P. Zeng, Appl. Microbiol. Biotechnol., 78, 917-926 (2008).

2) R. K. Saxena, P. Anand, S. Saran, J. Isar, Biotechnol. Adv., 27, 895-913 (2009).

3) G. Kaurr, A. K. Srivastava, S. Chand, Biochem. Eng. J., 64, 106-118 (2012).

4) S. G. Li, V. A. Tuan, J. L. Falconer, R. D. Noble, J. Membr. Sci., 191, 53-59 (2001).

5) F. Barbirato, E. H.Himmi, T. Conte, A. Bories, Ind. Crops Prod., 7, 281-289 (1998).

6) J. J. Malinowski, Biotechnol. Prog., 16, 76-79 (2000).

7) J. J. Malinowski, A. D. Daugulis, Sep. Sci. Technol., 37, 2659-2667 (2002).

8) J. Hao, H. Liu, D. Liu, Ind. Eng. Chem. Res., 44, 4380-4385 (2005).

9) J. Hao, F. Xu, H. Liu, D. Liu, J. Chem. Tech. Biotechnol., 81, 102-108 (2006).

10) M.H. Cho, S. I. Joen, S. H. Pyo, S. Mun, J. H. Kim, Process Biochem., 41, 739-744 (2006).

11) Y. J. Fang, P. Zhou, Sep. Sci. Technol., 41, 329-340 (2006).

12) Z. Li, B. Jiang, D. Zhang, Z. Xiu, Sep. Purif. Technol., 66, $472-478$ (2009).

13) T. A. Adams II, W. D. Seider, Chem. Eng. Res. Design, 87, 245-262 (2009).

14) T. Boonsongsawat, A. Shotipruk, V. Tantayakom, P. Prasitchoke, C. Chandavasu, P. Boonnoun, C. Muangnapoh, Sep. Sci. Technol., 45, 541-547 (2010).

15) P. Boonnoun, N. Laosiripojana, C. Muangnapoh, B. Jongsomjit, J. Panpranot, O. Mekasuwandumrong, A. Shotipruk, Ind. Eng. Chem. Res., 49, 12352-12357 (2010).

16) P. Anand, R. K. Saxena, R. G. Marwah, Appl. Microbiol. Biotechnol., 90, 1267-1276 (2011).

17) Z. Li, H. Teng, Z. Xiu, Process Biochem., 46, 586-591 (2011).

18) M. H. Chung, Y. K. Hong, H. W. Lee, S. J. Park, Adv. Mat. Phys. Chem., 2, 154-157 (2012).

19) Y. Qi, X. Xu, N. Li, Y. Fang, Sep. Sci. Technol., 47, 584-590 (2012).

20) A. Müller, A. Górak, Sep. Purif. Technol., 97, 130-136 (2012).

21) P. Barski, J. Kowalczyk, A. Lindstaedt, J. Puzewicz-Barska, D. Witt, Process Biochem., 47, 1005-1010 (2012).

22) H. S. Wu, Y. J. Wang, Ind. Eng. Chem. Res, 51, 10930 - 10935 (2012).

23) A. Müller, R. Schulz, J. Wittman, I. Kaplanow, A. Górak, RSC Adv., 3, 148-156 (2013).

24) Z. G. Li, Y. Q. Sun, W. L. Zheng, H. Teng, Z. L. Xiu, Biochem. Eng. J., 80, $68-75$ (2013).

25) H. Fu, Y. Sun, Z. Xiu, Process Biochem., 48, 1381-1386 (2013).

26) Z. Song, Y. Sun, B. Wei, Z. Xiu, Eng. Life Sci., 13, 487-495 (2013).

27) M. Matsumoto, A. Kado, T. Shiraki, K. Kondo, K. Yoshizuka, J. Chem. Tech. Biotechnol., 84, 1712-1716 (2009).

28) M. Matsumoto, R. Okuno, K. Kondo, Solvent Extr. Res. Dev., Jpn., 21, 181-190 (2014).

29) Y. Gu, C. Ogawa, S. Kobayashi, Chem. Lett., 35, 1176-1177 (2006).

30) N. Gupta, Sonu, G. L. Kad, J. Singh, Catal. Commun., 8, 1323-1328 (2007).

31) A. M. Saillenfait, F. Gallissot, G. Morel, P. Bonnet, Food Chem. Toxicol., 41, 415-429 (2003).

32) X. Sun, L. Cui, T. Xu, D. Wang, Adv. Mat. Res., 550-553, 400-403 (2012). 